Volume 3, Issue 1, February 2018, Pages: 236, DOI: http://dx.doi.org/10.19082/ah236

\title{
DYSLIPIDEMIA IN TYPE 2 DIABETES MELLITUS
}

\author{
Youb Imane ${ }^{1}$, Missoun Fatiha ${ }^{2}$, Karamane souad ${ }^{1}$, Bouabedelli Fatma ${ }^{2}$, Benhamimed El attafia ${ }^{2}$, Djebli \\ Noureddine ${ }^{2}$
}

1: Département of biology, University of Mostaganem.Algéria

2: Laboratory ofPharmacognosy and Api-Phytothérapy (LPAP), University of Mostaganem. Algeria

* Corresponding author: Missoun fatiha; fatiha.missoun@yahoo.fr.

\section{TYPE OF ARTICLE: CONFERENCE ABSTRACT}

\begin{abstract}
Background: Dyslipidemia is one of the major risk factors for cardiovascular disease in diabetes mellitus. The characteristic features of diabetic dyslipidemia are a high plasma triglyceride concentration, low HDL cholesterol concentration and increased concentration of small dense LDLcholesterol particles. The objective of this work was to define and characterize the lipid profile of type 2 diabetic patients

Methods: A series of 30 patients was selected for the study of the lipid profile; the classic methods were used for the determination of triglycerides, total cholesterol, C-HDL, and C-LDL.

Results: According to our results, all our patients had hyperglycemia, our patients had a body weight $\geq$ $80 \mathrm{~kg}$, with an overweight of $88 \%$ in women and $86.4 \%$ in men. All our patients had dyslipidemia with high levels of triglycerides and total cholesterol.

Conclusion: Lipid abnormalities are part of the metabolic disease and contribute to the increased cardiovascular risk of type 2 diabetes, intensive treatment of dyslipidemia becomes an absolute obligation in the cardiovascular prevention of these patients.

KEYWORDS: Diabetes type 2, Cardiovascular disease, Cholesterol, HDL-c, LDL-c
\end{abstract}

\footnotetext{
Abstracts of Second International Conference on Health Sciences and Medical Technologies, 10-12 October 2017, Tlemcen, Algeria (ICHSMT-17)

(C) 2018 The Authors. This is an open access article under the terms of the Creative Commons Attribution-NonCommercialNoDerivs License, which permits use and distribution in any medium, provided the original work is properly cited, the use is non-commercial and no modifications or adaptations are made.
} 